\title{
EVALUASI BUDAYA ORGANISASI DALAM PEMANFAATAN APLIKASI E-OFFICE UNTUK MENDUKUNG PENERAPAN E-GOVERNMENT PADA KESBANGPOL PROVINSI RIAU
}

\author{
Indah Permata Sari $^{1}$, Megawati ${ }^{2}$ \\ ${ }^{1,2}$ Program Studi Sistem Informasi Fakultas Sains dan Teknolog \\ Universitas Islam Negeri Sultan Syarif Kasim Riau \\ Jalan HR. Soebrantas KM 15 No. 155 Pekanbaru - Riau \\ Inndahpermata@gmail.com \\ ${ }^{2}$ megawati@uin-suska.ac.id
}

\begin{abstract}
Abstrak: Pertentangan yang timbul dalam penerapan E-Office menjadi masalah yang memerlukan penyesuaian dan keseimbangan budaya baru. Kurangnya koordinasi dari pimpinan, serta lemahnya pengaturan dalam menggunakan E-Office menyebabkan rendahnya kesadaran pegawai dalam menggunakan E-Office. Penelitian ini dimaksudkan untuk mengetahui budaya organisasi dalam pemanfaatan E-Office pada Kesbangpol. Evaluasi kecendrungan budaya organisasi menggunakan metode Organization Culture Assesment Instrument (OCAI) dan Evaluasi karakteristik individu dalam organisasi menggunakan metode Hofstede. Hasil pengukuran diketahui Kesbangpol menganut budaya Hierarchy dengan nilai 198,2. Ini menunjukkan instansi bersifat tersruktur dan terkontrol, dicirikan oleh suatu formalitas. Kedepannya Kesbangpol mengharapkan budaya Clan dengan nilai 188,7. Ini menunjukkan Kesbangpol menginginkan budaya kerja yang lebih kekeluargaan. Berdasarkan pengukuran menggunakan Hofstede, Diketahui bahwa Kesbangpol memiliki Long Term Orientation Index sangat tinggi yaitu sebesar 131,5, Ini menunjukkan kepribadian Pegawai Kesbangpol yang lebih menekankan cara pandang jauh kedepan. Hasil akhir dari penelitian ini berupa rekomendasi langkah strategis menggunakan Eight Immperatives yang menitikberatkan pada bagaimana Membuat rencana tentang pengembangan E-Office, memelihara sarana TI yang sudah ada.
\end{abstract}

Kata Kunci : Budaya Organisasi, Eight Immperatives, E-Office,Hofstede, OCAI

Abstract: The contradictions that arise in the application of E-Office are issues that require new cultural adjustments and balances. Lack of coordination from the leadership, as well as poor arrangements in using E-Office cause low awareness of employees in using E-Office. This research is intended to know the organizational culture in the utilization of E-Office on Kesbangpol. Evaluation of organizational culture tendency using Organization Culture Assessment Instrument (OCAI) method and Evaluation of individual characteristic in organization using Hofstede method. The measurement result is known Kesbangpol embrace Hierarchy culture with value of 198,2. This shows that agencies are structured and controlled, characterized by a formality. In the future Kesbangpol expect Clan culture with a value of 188.7. This shows that Kesbangpol wants a more family-friendly work culture. Based on measurements using Hofstede, it is known that Kesbangpol has a very long Long Orientation Index of 131.5, It shows the personality of Kesbangpol Employee which emphasizes the far worse perspective. The final result of this research is recommendations of strategic steps using Eight Immperatives which focuses on how to create a plan on E-Office development, maintaining existing IT facilities. Keywords: Organizational Culture, Eight Immperatives, E-Office, Hofstede, OCAI

\section{PENDAHULUAN}

Badan Kesatuan Bangsa dan Politik Provinsi Riau (Kesbangpol) merupakan suatu instansi pemerintahan yang memiliki tugas melakukan perlindungan terhadap masyarakat, Kesbangpol memiliki sikap dan perilaku individu ataupun kelompok yang didasari atas nilai-nilai yang diyakini kebenarannya dan telah menjadi sifat serta kebiasaan dalam melaksanakan tugas 
dan pekerjaan sehari-hari. Pola pikir dan cara kerja antara pimpinan dan pegawai pada Kesbangpol memiliki perbedaan. Sehingga cara pandang terhadap budaya organisasi juga berbeda. Pimpinan bekerja dengan Profesionalitas, tanggung jawab, dan loyalitas yang tinggi terhadap organisasi yang berada dibawahnya, sementara Pegawai memiliki pola pikir dan cara kerja sederhana yaitu bekerja sesuai dengan tugas yang diberikan oleh pimpinan.

Dalam menjalankan tugasnya Kesbangpol telah menerapkan sistem informasi untuk mendukung tercapainya tujuan organisasi dengan lebih cepat, efektif dan efesien. Salah satu layanan kegiatan perkantoran khususnya administrasi surat menyurat adalah E-Office. E-Office bertujuan untuk mempermudah proses administrasi surat menyurat baik surat dalam maupun luar Satuan Kerja Perangkat Daerah (SKPD) Provinsi Riau.

Namun dalam Penerapan E-Office terdapat masalah yaitu database kepegawaian yang digunakan sebagai dasar data pegawai pada $E$ Office jarang atau bahkan tidak pernah di update secara berkala, Selain masalah juga terjadi pada proses pengimplementasiannya, kegagalan implementasi didominasi oleh faktor pengguna yaitu adanya keterbatasan keahlian sehingga pegawai mengalami kesulitan untuk beradaptasi dengan sistem dikarenakan kebanyakan pegawai sudah berusia lebih dari 35 tahun, selain itu kurangnya koordinasi dari pimpinan dan lemahnya pengaturan dalam menggunakan E-Office yang ditunjukkan dengan tidak adanya tindakan tegas dari pimpinan kepada pegawai ketika terjadi kesalahan dalam penerapan IT. Kurangnya bimbingan/Pelatihan juga menyebabkan rendahnya kesadaran pegawai menggunakan e-office dalam proses administrasi surat menyurat, sehingga sebagian administrasi surat menyurat yang telah menggunkan E-Office tetap masih menggunakan sistem manual hal tersebut akan berpengaruh terhadap kinerja pegawai.

Berdasarkan permasalahan tersebut, jika dilihat dari budaya organisasi yang telah terbentuk, maka budaya yang terdapat Kesbangpol Provinsi Riau lemah dan akan sulit dalam pelaksanaan visi, misi dan tujuan secara efektif dan efesien. Tujuan penelitian ini adalah untuk mengetahui karakteristik budaya organisasi menggunakan Organization Culture Assesment Instrument (OCAI) dan mengetahui karakteristik individu dalam organisasi menggunakan Hofstede dan menghasilkan Rekomendasi langkah strategis untuk penerapan E-Office pada Badan Kesatuan Bangsa dan Politik Provinsi Riau.

\section{LANDASAN TEORI}

\subsection{E-Office}

Electronic Office (e-office) adalah suatu sistem yang berhubungan dengan administrasi, secara maya memusatkan komponen-komponen sebuah organisasi dimana data, informasi, dan komunikasi dibuat melalui media telekomunikasi. E-office merupakan software dan digunakan untuk mengatur pola pekerjaan yang sudah atau akan dilakukan oleh pegawai, menyimpan, dan mengontrol konten-konten yang ada didalam suatu organisasi secara elektronik [5].

\subsection{Budaya Organisasi}

Menurut Edgar Schein Budaya Organisasi adalah sebagai filosofi yang mendasari kebijakan organisasi, aturan main untuk bergaul dan perasaan atau iklim yang dibawa oleh persiapan fisik organisasi [2].

Adapun Sarplin menyatakan budaya organisasi merupakan suatu sistem nilai, kepercayaan dan kebiasaan dalam suatu organisasi yang saling berinteraksi dengan struktur sistem 
formalnya untuk menghasilkan norma-norma perilaku organisasi.[7]

\subsection{Organization Culture Assesment Instrument} (OCAI)

OCAI adalah instrumen dalam menggambarkan profil budaya organisasi. Instrumen ini merupakan suatu kerangka yang dikembangkan awalmya dari Competing Values Framework (CVF), sangat berguna dalam mencerminkan ke arah mana perusahaan dikelompokkan berdasarkan kulturnya yaitu budaya clan, adhocracy, hierarchy, atau market untuk mendukung misi dan tujuannya, dan juga untuk dapat mengidentifikasi elemen-elemen di dalam kultur yang dapat melawan misi dan tujuan. Hal ini juga bermanfaat, ketika sebuah perusahaan sedang mencari kembali jati dirinya dan mendefinisikan ulang kebudayaan di dalamnya, sehingga dapat mencari elemen apa saja yang dapat mendukung kegiatan perusahaan. [7]

\subsection{Dimensi Budaya OCAI}

Untuk menganalisis budaya organisasi, Competing Values Framework memiliki 6 variabel yang mewakili keempat budaya dalam OCAI. Karakteristik setiap dimensi dapat dilihat pada tabel 2.1.

Tabel 2.1 Dimensi Budaya [3]

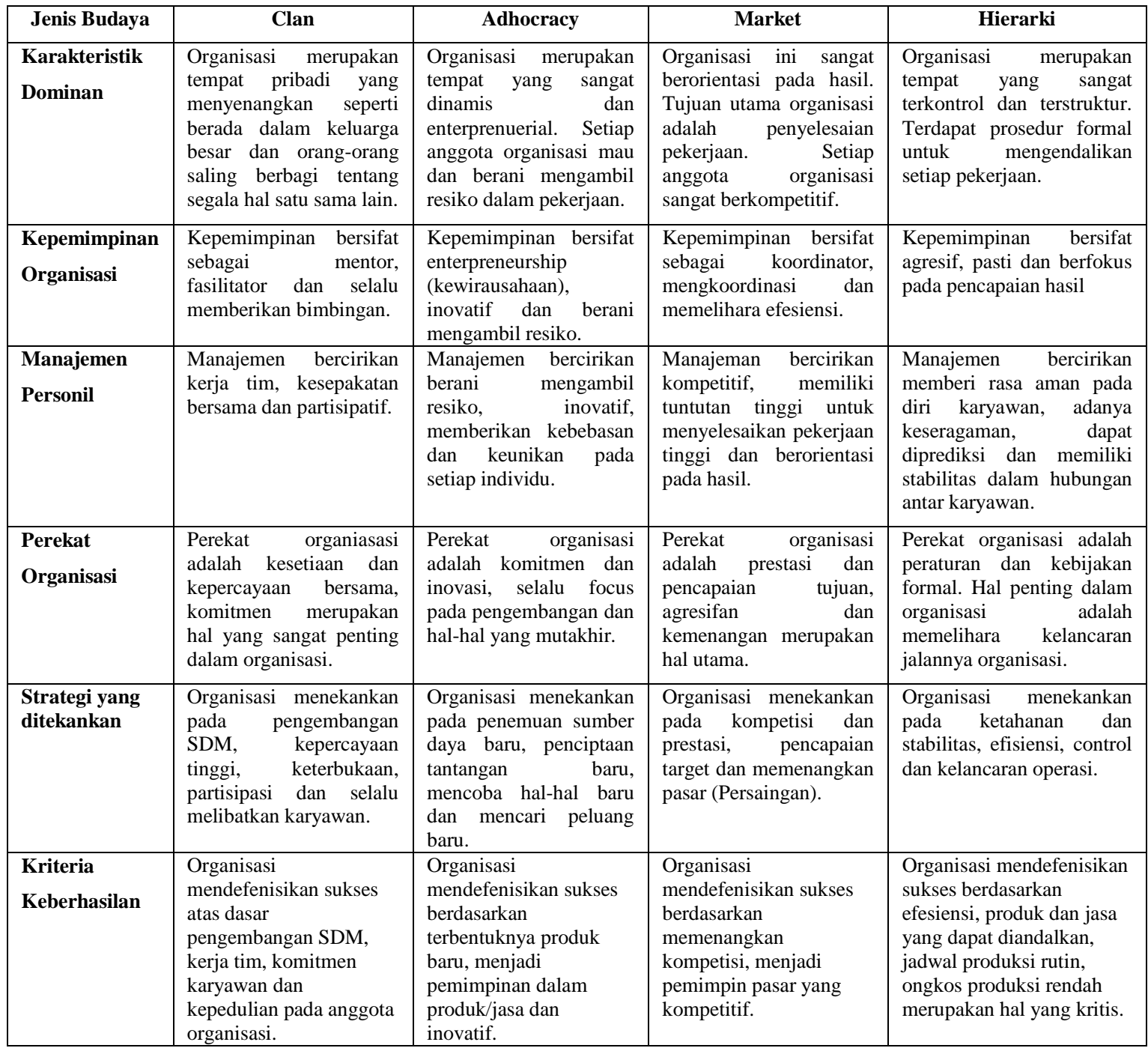




\subsection{Hofstede}

Pada VSM 13 Hofstede memperkenalkan 6 dimensi budaya yang digunakan untuk mengukur dan membandingkan budaya nasional suatu masyarakat. Dimensi dimensi tersebut adalah:

\section{Power Distance (PDI)}

Power Distance mengukur sejauh mana anggota sebuah organisasi/institusi yang tidak memiliki kekuasan menerima bahwa terdapat ketidakadilan distribusi kekuasaan pada organisasi/institusi tersebut. Dimensi ini merefleksikan nilai dari anggota masyarakat yang kurang memiliki kekuasaan serta nilai dari anggota masyarakat yang kurang memiliki kekuasaan serta nilai dari anggota masyarakat yang memiliki kekuasaan.[4]

\section{Individualism vs Collectivism (IDV)}

Dimensi Individualism, merupakan kecendrungan dari masyarakat untuk memperhatikan diri sendiri dan orang-orang dekat (pasangan, anak, orang tua). Ujung kontinum dari dimensi ini Collectivism, merupakan tendensi dari masyarakat untuk bergabung dalam kelompok dan kemudian saling menjaga satu sama lain dengan konsekuensi pertukaran loyalitas antar anggotanya [4].

\section{Masculinity vs Femininity (MAS)}

Dimensi masculinity merefleksikan situasi dimana nilai-nilai dominan dalam masyarakat adalah "success, money and possessions". Ujung kontinum lain dari dimensi ini adalah Femininity, yang merefleksikan masyarakat yang memiliki nilai-nilai dominan peduli terhadap sesama, harmoni dan ketenanan dalam hidup [4].

\section{Uncertainty avoidance (UAI)}

Dimensi Uncertainty Avoidance mengukur sejauh mana masyarakat merasa terancam terhadap situasi yang tidak pasti, tidak diketahui, ambigu dan tidak terstruktur. Masyarakat memiliki penghindaran ketidakpastian tinggi cendrung merasa terancam apabila menghadapi situasi yang tidak pasti, dan akan membentuk situasi yang tidak pasti, dan akan membentuk institusi untuk menghindari ketidakpastian ini. .[4]

\section{Long term orientation vs short term orientation (LTO)}

Masyarakat dengan orientasi jangka panjang menumbuhkan nilai-nilai yang terkait dengan reward dimasa depan, seperti kegigihan dan penghematan. Masyarakat dengan orientasi jangka pendek lebih menumbuhkan nilai-nilai terkait dengan masa lalu dan masa kini seperti penghormatan terhadap tradisi, menyelamatkan kewajiban sosial [4].

\section{Indulgence vs restraint (IVR)}

Dimensi Indulgence merefleksikan masyarakat yang dalam tatanan sosialnya sangat mentoleransi pengekspresian hasrat dan perasaan, terutama yang berkaitan dengan pemanfaatan waktu luang, mencari hiburan bersama teman, pembelian barang, konsumsi dan hal-hal yang berbau seksual. Ujung kontinum dari dimensi ini adalah restraint, yang merefleksikan masyarakat yang menahan kesenangan-kesenangan yang disebutkan sebelumnya. Masyarakat yang masuk dalam kategori ini cendrung kurang dapat menikamti hidup [4].

Tabel 2.2 Rumus Perhitungan Index VSM 2013[8]

\begin{tabular}{|l|l|}
\hline \multicolumn{1}{|c|}{ Dimensi } & \multicolumn{1}{c|}{ Rumus } \\
\hline Power Distance & $\mathrm{PDI}=35(\mathrm{~m} 07-\mathrm{m} 02)+$ \\
Index $($ PDI) & $25(\mathrm{~m} 20-\mathrm{m} 23)+\mathrm{C}(\mathrm{pd})$ \\
\hline Individualism vs & $\mathrm{IDV}=35(\mathrm{~m} 04-\mathrm{m} 01)+$ \\
Collectivism $(I D V)$ & $35(\mathrm{~m} 09-\mathrm{m} 06)+\mathrm{C}(\mathrm{ic})$ \\
\hline Mascullinity $v s$ & $\mathrm{MAS}=35(\mathrm{~m} 05-\mathrm{m} 03)+$ \\
Feminity $(M A S)$ & $35(\mathrm{~m} 08-\mathrm{m} 10)+\mathrm{C}(\mathrm{mf})$ \\
\hline Uncertainty & $\mathrm{UAI}=40(\mathrm{~m} 18-\mathrm{m} 15)+$ \\
Avoidance $(U A I)$ & $25(\mathrm{~m} 21-\mathrm{m} 24)+\mathrm{C}(\mathrm{ua})$ \\
\hline Long Term & $\mathrm{LTO}=40(\mathrm{~m} 13-\mathrm{m} 14)+$ \\
Orientation Index & $25(\mathrm{~m} 19-\mathrm{m} 22)+\mathrm{C}(\mathrm{ls})$ \\
\hline
\end{tabular}




\begin{tabular}{|l|l|}
\hline$($ LTO $)$ & \\
\hline Indulgence vs & $\mathrm{IVR}=35(\mathrm{~m} 12-\mathrm{m} 11)+$ \\
Restraint $(I V R)$ & $40(\mathrm{~m} 17-\mathrm{m} 16)+\mathrm{C}(\mathrm{ir})$ \\
\hline
\end{tabular}

\subsection{Eight Immperatives}

Delapan komando ini merupakan suatu tuntunan yang dirancang untuk membantu para pemimpin mengembangkan agenda aksinya. Delapan

Komando tersebut adalah:

1. Fokus pada bagaimana IT dapat membentuk ulang pekerjaan dan strategi-strategi sektor publik.

2. Gunakan IT untuk inovasi strategis, bukan hanya otomasi taktis.

3. Gunakan praktek terbaik untuk mengimplementasikan inisiatifinisiatif IT.

4. Tingkatkan penganggaran dan pembiayaan untuk inisiatif-inisiatif IT yang menjanjikan.

5. Lindungi privasi dan sekuriti.

6. Bentuk hubungan kerjasama yang berkaitan dengan IT untuk menstimulasi pengembangan ekonomi.

7. Gunakan IT untuk mempromosikan kesempatan yang sama dan komunitas yang sehat.[1]

\section{METODOLOGI}

Langkah-langkah dalam menevaluasi budaya organisasi dalam penelitian ini meliputi tahapantahapan sebagai berikut:

\section{A. Tahap Perencanaan}

Adapun kegiatan yang dilakukan pada tahap perencanaan:

\section{Perumusan Masalah}

Melakukan peninjauan ketempat penelitian yaitu Badan Kesatuan Bangsa dan Politik Provinsi Riau untuk meninjau penggunaan $E$ Office dan mengetahui masalah apa yang terjadi pada masalah tersebut.

\section{Penentuan Tujuan Penelitian}

Penentuan tujuan berfungsi untuk memperjelas tentang apa saja yang menjadi sasaran dari penelitian ini yaitu:

a. Mengetahui kecendrungan budaya organisasi menggunakan metode OCAI

b. Mengetahui karakteristik individu dalam organisasi menggunakan metode HOFSTEDE

c. Menghasilkan rekomendasi langkah strategis untuk penerapan IT menggunakan Eight Immperatives.

3. Penentuan Data

Untuk mempermudah penulis dalam melakukan evaluasi, maka perlu ditentukan beberapa data, seperti Teoriteori yang berhubungan dengan evaluasi kebudayaan Organisasi, Teknik evaluasi yang digunakan dalam mengaevaluasi kebudayaan organisasi, Menentukan data primer dan data sekunder yang akan digunakan dalam menganalisis kebudayaan organisasi tersebut

B. Tahap Pengumpulan Data

Adapun tahap pengumpulan datanya melalui observasi, Studi pustaka, Wawancara dan Kuesioner.

\section{Tahap Analisis dan Hasil Penelitian}

Pada tahap ini yang dilakukan adalah mengolah data yang didapat dari penyebaran kuesioner, hasilnya membentuk suatu analisis yang bertujuan untuk mengetahui budaya organisasi saat ini dan budaya organisasi yang diharapkan dari penyebaran kuesioner.

a. Analisis Responden

Dalam tahap ini yang dilakukan berupa analisis berdasarkan karakteristik-karakteristik 
responden yang dikelompokkan berdasarkan jenis kelamin, usia, dan pendidikan terakhir.

b. Analisis Budaya Organisasi OCAI

Analisis dilakukan untuk mengetahui budaya organisasi saat ini dan budaya organisasi yang diharapkan organisasi dengan penyebaran kuesioner. Setelah kuesioner dibagikan kepada responden, lalu dilakukan perhitungan terhadap kuesioner. Kuesioner ini terdiri dari 6 dimensi yang masing masing dimensi terdapat empat tipe budaya organisasi yaitu Clan, Adhocracy, Market, Hierarchy.

c. Analisis Budaya Organisasi HOFSTEDE

Analisis dilakukan untuk mengetahui karakteristik tiap individu dalam organisasi dengan penyebaran kuesioner. Setelah kuesioner dibagikan kepada responden lalu dilakukan perhitungan terhadap kuesioner. Kuesioner ini terdiri dari 6 dimensi yaitu Power Distance Index, Individualism Index, Masculinity Index, Uncertainty Avoidance Index, Long Term Orientation Index.

\section{Tahap Pembuatan Laporan}

Tahap terakhir dalam penelitian ini adalah membuat dokumentasi hasil penelitian berupa laporan Tugas akhir dan mempresentasikan hasil penelitian untuk mengetahui hasil analisa yang didapat dalam melakukan penelitian.

\section{IV.ANALISIS DATA DAN PERANCANGAN}

\subsection{Analisa Metode}

Dalam melakukan evaluasi penulis menggunakan tiga metode untuk pembuatan rekomendasi yang sesuai untuk penerapan teknologi Informasi pada Badan Kesatuan Bangsa dan Politik Provinsi Riau. Adapun metode tersebut adalah Organization Culture Assesment Instrument (OCAI) yang berfungsi untuk mengukur karakteristik budaya organisasi pada Badan Kesatuan Bangsa dan Politik Provinsi Riau. Metode yang kedua yaitu menggunakan model Hofstede (VSM 2013) yang berfungsi untuk mengukur karakteristik individu masing-masing pegawai pada Badan Kesatuan Bangsa dan Politik Provinsi Riau.

dan untuk membuat rekomendasi langkah strategis penerapan teknologi informasi penulis menggunakan metode Eigh Immperatives. Responden pada penelitian ini adalah seluruh pegawai yang mempunyai akun E-Office dengan jumlah 77 pegawai. Dari 77 kuesioner yang disebar hanya 73 kuesioner yang kembali.

\subsection{Analisis Budaya Saat ini}

Sebagai instansi yang berada dibawah naungan aparatur pemerintahan yang memiliki tugas melakukan perlindungan terhadap masyarakat, Kesbangpol memiliki sikap dan perilaku individu ataupun kelompok yang didasari atas nilai-nilai yang diyakini kebenarannya dan telah menjadi sifat serta kebiasaan dalam melaksanakan tugas dan pekerjaan sehari-hari. Pola pikir dan cara kerja antara pimpinan dan pegawai pada Kesbangpol memiliki perbedaan. Sehingga cara pandang terhadap budaya organisasi juga berbeda. Pimpinan bekerja dengan Profesionalitas, Integritas, tanggung jawab, dan loyalitas yang tinggi terhadap organisasi yang berada dibawahnya, sementara Pegawai memiliki pola pikir dan cara kerja sederhana yaitu bekerja sesuai dengan tugas yang diberikan oleh pimpinan.

\subsection{Hasil Pengukuran Budaya OCAI}

Berikut hasil pengukuran budaya OCAI pada Badan Kesatuan Bangsa dan Politik Provinsi Riau; 
Tabel 4.1 Budaya OCAI pada Kesbangpol

\begin{tabular}{|l|l|l|}
\hline Budaya & Saat Ini & Diharapkan \\
\hline Clan (A) & 136,0 & 188,7 \\
\hline Adhocracy (B) & 131,2 & 137,2 \\
\hline Market (C) & 134,6 & 140,0 \\
\hline Hierarchy (D) & 198,2 & 134,1 \\
\hline
\end{tabular}

Hasil perolehan rata-rata nilai dimensi budaya OCAI pada Badan Kesatuan Bangsa dan Politik Provinsi Riau dapat dilihat dalam bentuk grafik seperti terlihat pada gambar 4.1

Tabel 4.2 Budaya Hofstede pada Kesbangpol

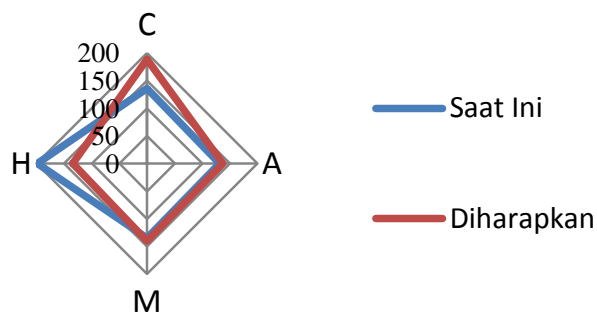

Gambar 4.1 Budaya OCAI Kesbangpol

Dari grafik pada Gambar 4.1 dapat diketahui penilaian budaya organisasi saat ini dan budaya organisasi yang diharapkan pada Badan Kesatuan Bangsa dan Politik Provinsi Riau. Hasil persentase budaya organisasi saat ini, tipe budaya organisasi teringgi pada Hierarchy Culture yaitu sebesar 198,2, Hal ini menunjukkan bahwa Badan Kesatuan Bangsa dan Politik Provinsi Riau memiliki ciri organisasi yang tersruktur dan terkontrol, adanya peraturan dan prosedur dalam penggunaan aplikasi E-Office untuk mendukung penerapan E-Government yang dibuktikan dengan adanya peraturan tentang kebijakan dan strategi nasional pengembangan E-Government melalui intruksi presiden No.3 Tahun 2003. Pimpinan bertindak sebagai koordinator dalam proses penerapan aplikasi $E$-Office.

Sedangkan untuk kondisi masa yang akan datang, nilai rata-rata tertinggi adalah 188,7 berada pada Clan Culture, Hal ini menujukkan untuk kedepannya Badan Kesatuan Bangsa dan Politik menginginkan budaya kerja yang lebih kekeluargaan dalam menggunakan aplikasi $E$ Office, dimana para pegawai dapat bekerjasama serta terlibat langsung dalam proses pengembangan layanan E-Office. Pimpinanan harus memberikan arahan dan pelatihan atau sosialisasi mengenai penggunaan E-Government khususnya E-Office agar pegawai dapat dengan cepat terlibat dalam penggunaan E-Office.

\subsection{Hasil Pengukuran Budaya Hofstede}

Hasil pengukuran Budaya Hofstede pada Badan Kesatuan Bangsa dan Politik Provinsi Riau dapat dilihat pada tabel 4.2.

Tabel 4.2 Hasil pengukuran Budaya Hofstede

\begin{tabular}{|c|c|c|c|}
\hline 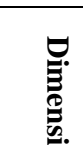 & $\begin{array}{c}\text { Rumus } \\
\text { Perhitungan } \\
\text { Indeks Skala } \\
\text { VSM } 2013\end{array}$ & $\begin{array}{l}\text { Perhitungan } \\
\text { Indeks } \\
\text { Skala VSM } \\
2013\end{array}$ & Hasil \\
\hline PDI & $\begin{array}{l}\text { PDI }=35(\mathrm{~m} 07 \\
-\mathrm{m} 02)+ \\
25(\mathrm{~m} 20-\mathrm{m} 23) \\
+\mathrm{C}(\mathrm{pd})\end{array}$ & $\begin{array}{l}\mathrm{PDI}=35 \\
(2,7-2,3)+ \\
25(2,9-2,3) \\
+50\end{array}$ & $\begin{array}{c}79 \\
\text { Large }\end{array}$ \\
\hline IDV & $\begin{array}{l}\mathrm{IDV}=35(\mathrm{~m} 04 \\
-\mathrm{m} 01)+ \\
35(\mathrm{~m} 09-\mathrm{m} 06) \\
+\mathrm{C}(\mathrm{ic})\end{array}$ & $\begin{array}{l}\text { IDV }= \\
35(2,2-2,0)+ \\
35(2,1-1,8)+ \\
50\end{array}$ & $\begin{array}{c}67,5 \\
\text { Individualis } \\
m\end{array}$ \\
\hline MAS & $\begin{array}{l}\mathrm{MAS}=35(\mathrm{~m} 05 \\
-\mathrm{m} 03)+ \\
35(\mathrm{~m} 08-\mathrm{m} 10) \\
+\mathrm{C}(\mathrm{mf})\end{array}$ & $\begin{array}{l}\text { MAS = } \\
35(1,7-1,8)+ \\
35(2,0-2,1)+ \\
50\end{array}$ & $\begin{array}{c}43 \\
\text { Feminism }\end{array}$ \\
\hline LTO & $\begin{array}{l}\mathrm{LTO}=40(\mathrm{~m} 13 \\
-\mathrm{m} 14)+ \\
25(\mathrm{~m} 19-\mathrm{m} 22) \\
+\mathrm{C}(1 \mathrm{~s})\end{array}$ & $\begin{array}{l}\text { LTO }= \\
40(2,9-2,3)+ \\
25(4,2-1,9)+ \\
50\end{array}$ & $\begin{array}{c}131,5 \\
\text { Long Term } \\
\text { Orientation }\end{array}$ \\
\hline IVR & $\begin{array}{l}\mathrm{IVR}=40(\mathrm{~m} 12 \\
-\mathrm{m} 11)+ \\
25(\mathrm{~m} 17-\mathrm{m} 16) \\
+\mathrm{C}(\mathrm{ir})\end{array}$ & $\begin{array}{l}\mathrm{IVR}= \\
40(2,6-2,5)+ \\
25(3,5-2,2)+ \\
50\end{array}$ & $\begin{array}{c}86,5 \\
\text { Indulgence }\end{array}$ \\
\hline
\end{tabular}

Berdasarkan tabel 4.2 diketahui Dimensi

Long Term Orientation pada Badan Kesatuan Bangsa dan Politik Provinsi Riau memiliki point tertinggi yaitu sebesar 131,5. Ini menjunjukkan kepribadian Pegawai Badan Kesatuan Bangsa dan Politik Provinsi Riau yang lebih menekankan cara pandang jauh kedepan yang cendrung menganggap segala hal sebagai investasi yang menguntungkan kedepannya. Bukan hanya tentang 
kelanggengan dalam pekerjaan tetapi juga memikirkan akan kelangsungan dari organisasi. Dengan nilai Long Term Orientation yang sangat tinggi memungkinkan para pegawai dapat meningkatkan E-Office jangka panjang untuk dunia digital agar dapat digunakan secara sempurna dan sesuai dengan kegunaan E-Office tersebut.

Dimensi budaya Indulgence vs Restraint pada Badan Kesatuan Bangsa dan Politik Provinsi Riau memiliki point sebesar 86,5. Hal ini menunjukkan bahwa Badan Kesatuan Bangsa dan Politik Provinsi Riau menganut budaya Indulgence, Dimensi ini merefleksikan pegawai pada kesbangpol dapat mengimplmentasikan aplikasi E-Office tanpa adanya batasan-batasan yang mengikat secara berlebihan. Seperti halnya penyediaan layanan informasi yang dapat menjadi media Sharing ketika terjadi masalah dalam proses pengimplemantasian E-Office baik untuk kepentingan didalam maupun diluar instansi.

Dimensi Budaya Power Distance pada Badan Kesatuan Bangsa dan Politik Provinsi Riau memiliki point sebesar 79. Hal ini menunjukkan emosional antara atasan dan bawahan pada Badan Kesatuan Bangsa dan Politik Provinsi Riau relatif besar. Terdapat kesenjangan kekuasaan yang menyebabkan pegawai memiliki atasan langsung yang dapat dihormati. Pegawai Badan Kesatuan Bangsa dan Politik Provinsi Riau menganggap hubungan antara atasan dan bawahan mirip dengan hubungan antara orang tua dan anak.. Jadi dalam hubungan kerja atasan dan bawahan, bukan hanya profesionalitas kerja yang perlu dilakukan namun kesantunan dalam bersikap juga merupakan suatu keharusan. Dengan nilai Power Distance yang tinggi ini pimpinan Kesbangpol dapat membangun komunikasi yang baik dalam hal penggunaan aplikasi E-Office dengan pegawai untuk mendukung penerapan aplikasi E-Office dalam proses administrasi surat menyurat.

Dimensi Budaya Uncertainty Avoidance pada Badan Kesatuan Bangsa dan Politik Provinsi Riau memiliki point sebesar 78. Hal ini menunjukkan bahwa pegawai mempunyai upaya untuk mengontrol emosi dalam merespon ketidakpastian situasi. Badan Kesatuan Bangsa dan Politik Provinsi Riau mempunyai tanggung jawab yang besar dalam proses administrasi surat menyurat menggunakan aplikasi E-Office Sehingga Cendrung mempunyai Skor UAI yang tinggi karena dalam menjalankan tugas harus bisa mengontrol emosi terhadap situasi yang tidak pasti. Dengan Uncertainty Avoidance index yang tinggi ini Diharapkan Kesbangpol dapat menilai resiko dari IT, Khususnya anggaran mengenai penerapan E-Office seperti menambah hardware untuk kepentingan E-Office seperti Printscreen.

Dimensi Budaya Individualism pada Badan Kesatuan Bangsa dan Politik Provinsi Riau memiliki point sebesar 67,5. ini menunjukkan bahwa nilai budaya Badan Kesatuan Bangsa dan Politik Provinsi Riau cendrung pada Individualism yang menunjukkan bahwa pegawai pada kesbagpol lebih mementingkan kepentingan pribadi Sehingga berdampak dalam hal penerapan aplikasi E-Office, pegawai belum dapat menyesuaikan diri dengan aplikasi E-Office dikarenakan baik atasan maupun bawahan cendrung kurang responsif ketika terjadi kesalahan dalam penggunaan aplikasi E-Office.

Dimensi Budaya Masculinity pada Badan Kesatuan Bangsa dan Politik Provinsi Riau rendah yaitu 43, artinya nilai budaya organisasi pada Badan Kesatuan Bangsa dan Politik Provinsi Riau lebih Condong ke Budaya Feminism. Meskipun dimensi Masculine lebih identik dengan perbedaan biologi yaitu laki-laki dan perempuan, namun seorang laki-laki bisa berkelakuan Feminim dan 
juga sebalikknya. Pada Badan Kesatuan Bangsa dan politik Provinsi Riau yang merefleksikan pegawai memiliki nilai-nilai dominan peduli terhadap sesama, harmoni dan ketenangan dalam hidup.

\subsection{Eight Immperatives}

\section{Imperative 1}

Berdasarkan hasil pengukuran budaya organisasi dengan menggunakan metode OCAI kesbangpol mengharapkan budaya Clan dimasa yang akan datang, maka langkah strategis yang harus dilakukan ialah pimpinanan harus memberikan arahan dan pelatihan atau sosialisasi mengenai penggunaan E-Government khususnya E-Office agar pegawai dapat dengan cepat terlibat dalam penggunaan E-office.

Dengan nilai Power Distance yang besar pimpinan dapat membangun komunikasi dengan pegawai yang mendukung proses administrasi surat menyurat dibantu dengan aplikasi E-Office, membuat Job Description, identifikasi pekerjaan yang lebih jelas untuk melakukan pembaharuan database kepegawaian secara berkala.

\section{Imperative 2}

Berdasarkan hasil pengukuran budaya organisasi dengan menggunakan metode OCAI, kesbangpol mengharapkan budaya Clan dimasa yang akan datang, maka langkah strategis yang harus dilakukan ialah organisasi bekerjasama serta melibatkan pegawai dalam proses pengembangan layanan E-Office dengan harapan seluruh pegawai dapat menerima sistem baru.

Dengan nilai Long Term Orientation yang sangat tinggi memungkinkan para pegawai dapat bekerja secara Remote (Melalaui alat Telecommutig atau perangkat Mobile) Dengan mengembangkan layanan E-office berbasis mobile yang dapat meningkatkan kualitas dan kemudahan dalam akses informasi kapan dan dimanapun.

\section{Imperative 3}

Berdasarkan hasil pengukuran budaya organisasi dengan menggunakan metode OCAI kesbangpol mengharapkan budaya Clan dimasa yang akan datang, maka langkah strategis yang harus dilakukan ialah instansi dapat membentuk tim pengembangan E-Office yang akan meningkatkan kualitas pekerjaan dan pendelegasian pekerjaan yang lebih jelas. Tempatkan pimpinan yang memiliki kemampuan yang baik berkaitan dengan penggunaan E-Office pada setiap bidang sehingga dapat mempermudah pegawai untuk berdiskusi ketika terjadi masalah dalam penggunaan E-Office.

Berdasarkan penilaian budaya organisasi menggunakan Hofstede diketahui bahwa Kesbangpol menganut budaya Individualism maka langkah strategis yang harus dilakukan ialah diharapkan pegawai Kesbangpol tidak hanya mengutamakan kepentingngan sendiri, namun harus lebih memperhatikan kebutuhan kelompok dengan cara kemendayagunakan aplikasi E-Office dengan sebaik mungkin dengan mengkomunikasikan strategi keseluruh bidang.

\section{Imperative 4}

Berdasarkan hasil pengukuran budaya organisasi dengan menggunakan metode OCAI kesbangpol mengharapkan budaya Clan dimasa yang akan datang, maka langkah strategis yang harus dilakukan ialah Kesbangpol dapat fokus kepada suatu diskusi anggaran yang penting dalam IT.

Berdasarkan hasil penilaian budaya organisasi menggunakan Hofstede menunjukkan bahwa pegawai Kesbangpol mempunyai upaya dalam merespon ketidakpastian situasi. Diharapkan 
Kesbangpol dapat menilai resiko dari IT, Khususnya anggaran mengenai penerapan E-Office seperti menambah hardware untuk kepentingan $E$ Office seperti Printscreen.

\section{Imperative 5}

Berdasarkan hasil pengukuran budaya organisasi dengan menggunakan metode OCAI kesbangpol mengharapkan budaya Clan dimasa yang akan datang, maka langkah strategis yang harus dilakukan ialah melakukan sosialisasi penggunaan dan pengelolaan IT yang baik pada seluruh pegawai.Dalam hal ini dapat diterapkan perlindungan privasi dan keamanan untuk mengatur hak akses setiap pegawai yang ada di masing-masing unit kerja terkait dengan adanya sistem informasi yang terintegrasi dan keamanan jaringan secara keseluruhan.

\section{Imperative 6}

Berdasarkan hasil pengukuran budaya organisasi dengan menggunakan metode OCAI kesbangpol mengharapkan budaya Clan dimasa yang akan datang, maka langkah strategis yang harus dilakukan ialah dapat menyediakan programprogram pelatihan yang sudah dilaksanakan saat ini harus diusahakan untuk dapat lebih baik lagi dengan mendayagunakan dukungan teknologi informasi yang terbaru.

Berdasarkan hasil penilaian budaya organisasi menggunakan Hofstede menunjukkan bahwa pegawai Kesbangpol menganut budaya Indulgence. Diharapkan pegawai Kesbangpol dapat menyediakan layanan informasi yang unggul, baik untuk kepentingan didalam maupun diluar instansi.

\section{Imperative 7}

Berdasarkan hasil pengukuran budaya organisasi dengan menggunakan metode OCAI kesbangpol mengharapkan budaya Clan dimasa yang akan datang, maka langkah strategis yang harus dilakukan ialah melakukan pengembangan pendidikan bebasis internet, pengembangan karir dan keterlibatan pegawai yang diperlukan untuk kesuksesan sosial dan ekonomi.

Dengan nilai Long Term Orientation yang sangat tinggi memungkinkan para pegawai dapat meningkatkan E-Office jangka panjang untuk dunia digital agar dapat digunakan secara sempurna dan sesuai dengan kegunaan E-Office tersebut.

\section{Imperative 8}

Berdasarkan hasil pengukuran budaya organisasi dengan menggunakan metode OCAI kesbangpol mengharapkan budaya Clan dimasa yang akan datang, maka langkah strategis yang harus dilakukan ialah pegawai dapat berpartisipasi dalam menyediakan dukungan teknologi informasi yang cerdas yang dapat digunakan untuk menyebarluaskan usaha untuk memperluas informasi dan pelayanan secara resmi dan mudah diakses. Dan dimana terdapat perkembangan tekologi informasi yang semakin pesat memungkinkan untuk mengembangkan instansi menjadi instansi digital.

\section{PENUTUP}

\subsection{Kesimpulan}

Berdasarkan uraian dan Pembahasan dari seluruh bab, maka dapat disimpulkan hasil penelitian ini beruba:

1. Berdasarkan pengukuran Budaya Organisasi menggunakan OCAI di Badan Kesatuan Bangsa dan Politik Provinsi Riau, Maka diketahui;

a. Budaya Organisasi saat ini adalah budaya Hierarchy yaitu sebesar 198,2 point. Hal 
ini menunjukkan bahwa Badan Kesatuan

Bangsa dan Politik Provinsi Riau memiliki ciri organisasi yang tersruktur dan terkontrol, adanya peraturan dan prosedur dalam penggunaan aplikasi $E$ Office untuk mendukung penerapan $E$ Government yang dibuktikan dengan adanya peraturan tentang kebijakan dan strategi nasional pengembangan $E$ Government melalui intruksi presiden No.3 Tahun 2003. Pimpinan bertindak sebagai koordinator dalam proses penerapan aplikasi E-Office.

b. Budaya Organisasi yang diharapkan adalah tipe budaya Clan yaitu sebesar 188,7 point. Hal ini menujukkan untuk kedepannya Badan Kesatuan Bangsa dan Politik menginginkan budaya kerja yang lebih kekeluargaan dalam menggunakan aplikasi E-Office, dimana para pegawai dapat bekerjasama serta terlibat langsung dalam proses pengembangan layanan $E$ Office. Pimpinanan harus memberikan arahan dan pelatihan atau sosialisasi mengenai penggunaan E-Government khususnya E-Office agar pegawai dapat dengan cepat terlibat dalam penggunaan E-office.

2. Berdasarkan pengukuran Budaya Organisasi menggunakan Hofstede, Diketahui bahwa Kesbangpol memiliki Long Term Orientation Index yang sangat tinggi yaitu sebesar 131,5 point, Ini menjunjukkan kepribadian Pegawai Kesbangpol yang lebih menekankan cara pandang yang jauh kedepan yang memungkinkan Kesbangpol dapat meningkatka E-Office jangka panjang untuk dunia digital agar dapat digunakan secara sempurna dan sesuai dengan kegunaan $E$ Office.

3. Rekomendasi dari Eight Immperatives berupa langkah-langkah yang menitikberatkan pada bagaimana teknologi informasi dapat membentuk ulang pekerjaan, TI digunakan sebagai langkah strategis kerja bukan sekedar otomasi taktis, mengembangkan kemampuan dan wawasan IT, membangun layanan yang mendukung proses bisnis instansi memelihara sarana IT yang telah tersedia dan meningkatkan akses jaringan baik dari segi sarana maupun prasarana.

\subsection{Saran}

Berdasarkan hasil penelitian pada Badan Kesatuan Bangsa dan Politik Provinsi Riau, maka penulis mencoba memberikan saran yang diharapkan dapat menjadi masukan bagi organisasi, yaitu:

1. Perlu diadakan penelitian lebih lanjut tentang pengaruh kultur organisasi terhadap strategi penerapan Teknologi Informasi.

2. Berdasarkan hasil pengukuran Budaya Organisasi menggunakan OCAI, Pegawai Badan Kesatuan Bangsa dan Politik Provinsi Riau mengharapkan perubahan budaya menjadi lebih kekeluargaan, sehingga dapat dilakukan rencana strategis untuk perubahan budaya yang tepat bagi Badan Kesatuan Bangsa dan Politik Provinsi Riau untuk yang akan datang .

\section{REFERENSI}

[1] Aditya, Bayu Rima., 2015. “ Perencanaan Strategis Sistem Informasi Berdasarkan Budaya Organisasi Dan 8 Komando Pimpinan (studi kasus: Fakultas Ilmu Terapan Universitas Telkom)", Seminar Nasional Teknologi Informasi dan Multimedia. ISSN: 2302-3805. 6-8 Februari 2015

[2] Chatab, Novizond., 2007. Profil Budaya Organisasi: Mendiagnosis Budaya dan Merangsang Perubahannya. Bandung: Alfabeta 
Jurnal Pseudocode, Volume V Nomor 1, Februari 2018, ISSN 2355-5920 www.ejournal.unib.ac.id/index.php/pseudocode

[3] Megawati. "Analisis Strategi Penerapan Teknologi Informasi dalam Membentuk Budaya Organisasi yang Islami Menggunakan Model Hofstede". ISSN: 23551941. 2013.

[4] Perdhana, Mirwan Surya., 2015. “ Perhitungan Nilai Budaya dengan Menggunakan Value Survey Module 2008: Sebuah Telaah Kritis”. Jurnal Bisnis Strategi Vol. 24 No.1

[5] Prayuda, 2012 "Penerapan E-Office Dalam Hubungan antara Front Office dan Back Office Di PT. Kereta Api Indonesia (Persero)". Skripsi Universitas Indonesia. Depok.

[6] Rangkuti, Freddy, 2013. "Analisis SWOT: Teknik membedah kasus Bisnis cara perhitungan bobot, Rating dan OCAI." Jakarta: Gramedia Pustaka Utama.

[7] Riani, Asri Laksmi, 2011. “ Budaya Organisasi”. Yogyakarta: Graha Ilmu

[8] Siregar, Laura Nopianti. dkk, 2016 “ Penilaian Budaya Organisasi Perguruan Tinggi Menggunakan Value Survey Module 2013 Hofstede di Universitas Telkom Bandung" . Seminar Nasional Sistem Informasi Indonesia. 